\begin{tabular}{|l|l|}
\hline SITAS & $\begin{array}{l}\text { JANHUS Journal of Animal Husbandry Science } \\
\text { Jurnal Ilmu Peternakan } \\
\text { Fakultas Pertanian, Universitas Garut } \\
\text { P ISSN : 2548-7914, E ISSN : 2775-0469 }\end{array}$ \\
\hline
\end{tabular}

\title{
PENGARUH SUBSTITUSI DEDAK PADI DENGAN BONGGOL PISANG TERFERMENTASI TERHADAP SIFAT FISIK PELLET
}

\section{(The Influence of Substitution of Rice Bran by Fermented Banana Corm on Physical Characters of Pellets)}

\author{
Slamet Raharja ${ }^{1,}$ Titin Nurhayatin $^{2}$ dan Ervi Herawati ${ }^{3}$ \\ ${ }^{1}$ Alumni Program Studi Peternakan, Fakultas Pertanian, Universitas Garut \\ ${ }^{2,35}$ Program Studi Peternakan, Fakultas Pertanian, Universitas Garut \\ Email: \\ titinnurhayatin@uniga.co.id
}

\begin{abstract}
Abstrak
Penelitian ini bertujuan untuk mengetahui pengaruh dari substitusi dedak padi dengan bonggol pisang terfermentasi terhadap kerapatan tumpukan, kerapatan pemadatan tumpukan, berat jenis, dan sudut tumpukan pellet. Persiapan bahan dan Pengujian sifat fisik pellet dilaksanakan di Laboratorium terpadu Fakultas Pertanian Universitas Garut. Metode yang digunakan dalam penelitian ini yaitu metode eksperimental dengan menggunakan Rancangan Acak Lengkap (RAL) terdiri dari 5 perlakuan dan 4 ulangan, yaitu : $\mathrm{R}_{0}$ (dedak padi $5 \%$, bonggol pisang terfermentasi $0 \%$ ), $\mathrm{R}_{1}$ (dedak Padi 3,75\%, bonggol pisang terfermentasi 1,25\%), $\mathrm{R}_{2}$ ( dedak padi $2,5 \%$, bonggol pisang terfermentasi $2,5 \%$ ), $\mathrm{R}_{3}$ (dedak padi $1,25 \%$, bonggol pisang terfermentasi $3,75 \%$ ), dan $\mathrm{R}_{4}$ (dedak padi $0 \%$, bonggol pisang terfermentasi $5 \%$ ). Data penelitian dianalisis menggunakan sidik ragam dan bila hasilnya berbeda nyata dilanjutkan dengan Uji Jarak Berganda Duncan untuk melihat perbedaan antar perlakuan. Hasil penelitian menunjukkan bahwa substitusi dedak padi dengan bonggol pisang terfermentasi berpengaruh terhadap kerapatan tumpukan dan kerapatan pemadatan tumpukan, tetapi tidak berpengaruh terhadap berat jenis dan sudut tumpukan pellet. Perlakuan paling optimal yaitu pada perlakuan $\mathrm{R}_{1}$ (dedak padi $3,75 \%$, bonggol pisang terfermentasi $1,25 \%$ ).
\end{abstract}

Kata kunci: Bonggol Pisang Terfermentasi, Pellet, Sifat fisik.

\begin{abstract}
The research aim was to know the influence of substituting of rice bran by banana corm fermented on stack density, stack compaction density, specific gravity and pellet stack angle. The preparation of materials and physical pellets test was carried out at Faculty of Agriculture Laboratory Universitas Garut. The method used is Experimental Method using a Completely Randomized Design (CRD) with 5 treatments and 4 replication. The treatments used were $R_{0}(5 \%$ rice bran, $0 \%$ banana corm fermented; $R_{1}$ (rice bran $3,75 \%$, banana corm $1,25 \%$, fermented), $R_{2}$ $(2,50 \%$ rice bran, banana corm fermented $2,50 \%), R_{3}$ (rice bran $1,25 \%$, banana corm $3.75 \%$ fermented), and $R_{4}(0 \%$ Rice Bran, Banana corm $5 \%$ fermented. The
\end{abstract}


results data were analyzed using analysis of variance and if the results were significantly different by Duncan's Multiple Range Test to see the differences between treatments. The results showed that substituting of rice bran by banana corm fermented had a significant effect on stack density, stack compaction density but had not a significant effect on specific gravity and stack angle pellets. The highest value of treatments was $R_{1}$ (rice brand 3,75\%, banana corm1,25\% fermented).

Keywords: Banana Corm Fermented, Pellets, Physical characters.

\section{Pendahuluan}

Pakan merupakan salah satu penentu keberhasilan dalam manajemen peternakan. Kualitas dan kuantitas pakan sering menjadi kendala yang harus dihadapi dalam upaya memenuhi kebutuhan hidup pokok, pertumbuhan, produksi dan reproduksi ternak. Untuk itu harus dicari sumber bahan pakan pengganti atau alternatif dengan nilai nutrisi yang cukup, murah, ketersediaanya cukup banyak, kesinambungannya terjamin, serta aman dikonsumsi ternak.

Salah satu limbah yang berpotensi digunakan untuk pakan ternak adalah bonggol pisang. Tanaman ini merupakan tanaman yang banyak tumbuh di Indonesia. Kandungan serat kasar dalam bonggol pisang cukup tinggi sehingga dibutuhkan suatu proses untuk menurunkan serat kasar, meningkatkan nilai nutrisi sekaligus mengawetkan bahan pakan yaitu dengan menggunakan teknologi fermentasi. Bonggol pisang yang telah difermentasi atau terfermentasi diharapkan dapat mensubtitusi penggunaan dedak padi dalam ransum ternak.

Pellet adalah ransum yang dibuat dengan mengggiling bahan baku, mencampur, memadatkan dengan menggunakan binder / perekat dengan bentuk diameter , panjang dan ukuran yang sama. Ransum dalam bentuk pellet mempunyai kelebihan diantaranya dapat meningkatkan konsumsi pakan ternak, mengurani jumlah pakan yang terbuang, memperpanjang penyimpanan, dan mempermudah pengangkutan.

Bonggol pisang dapat diperoleh dari pohon pisang yang telah dipanen buahnya juga dari pohon pisang yang telah tua. Pertumbuhan dan perkembangan pohon pisang cepat, menjadikan ketersediaan bonggol pisang sangat melimpah sehingga mempunyai potensi yang baik sebagai bahan baku untuk pakan ternak. Kandungan nutrisi bonggol pisang menurut Sunarto dkk., (2013) memiliki komposisi $76 \%$ pati, $20 \%$ air sisanya protein dan vitamin. Bonggol pisang, khususnya bonggol pisang yang kering, mempunyai kandungan karbohidrat yang tinggi, yaitu 66,2 \%. Jika dibandingkan dengan beras yang mempunyai kandungan karbohidrat sebanyak 76,2\%, Ubi Kayu (Gaplek) 81,3\%, dan Jagung 63,6\%, maka bonggol pisang juga mengandung karbohidrat yang tidak jauh berbeda.

Pellet adalah ransum yang dibuat dengan mengggiling bahan baku, mencampur, memadatkan dengan menggunakan binder perekat dengan bentuk, diameter, panjang dan ukuran yang sama. Ransum dalam bentuk pellet mempunyai kelebihan diantaranya dapat meningkatkan konsumsi pakan ternak, mengurani jumlah pakan yang terbuang, memperpanjang penyimpanan, dan mempermudah pengangkutan.

Bahan yang digunakan yang untuk pellet berpengaruh terhadap sifat fisik pellet. Sifat fisik pellet diantaranya yaitu berat jenis, sudut tumpukan, kerapatan tumpukan dan kerapatan pemadatan tumpukan. Bonggol pisang terfermentasi mengandung KH 76\% sehingga mengalami gelatinisasi 
bila dijadikan pellet karena ada pemanasan menurut (Sunarto dkk., 2013). Bonggol pisang fungsinya hampir sama dengan tepung gaplek dalam pembuatan pellet. Penggunaan tepung gaplek 5\%, dan tepung tapioka 2-6\% memberikan pengaruh yang baik pada sifat fisik pellet (Syamsu, 2007). Berdasarkan kerangka pemikiran diatas maka penggunaan bonggol pisang fermentasi sampai $5 \%$ menghasilkan sifat fisik pellet yang optimal.

\section{Metodologi}

\subsection{Waktu dan Tempat}

Waktu penelitian pada bulan April sampai Juli 2018. Pengujian sifat fisik pellet dilaksanakan di laboratorium Fakultas Pertanian Universitas Garut Jl. Raya Samarang, No. 52 A, Tarogong Kaler Kabupaten Garut.

\subsection{Objek Penelitian}

\section{Bahan Pakan Penyusun Pellet}

Bahan pakan penyusun pellet yang digunakan yaitu jagung, tepung ikan, dedak, bungkil kedelai, bonggol pisang ambon hasil fermentasi, CPO, tepung tulang, dan premix. Komposisi bahan pakan penyusun pellet percobaan tertera pada Tabel 1 .

Tabel 1. Komposisi Pellet Perlakuan

\begin{tabular}{llllll}
\hline \multirow{2}{*}{ Bahan Pakan } & \multicolumn{5}{c}{ Perlakuan } \\
\cline { 2 - 6 } & R0 & R1 & R2 & R3 & R4 \\
\hline Tepung Jagung & 56,5 & 56,5 & 56,5 & 56,5 & 56,5 \\
Bungkil Kedelai & 26 & 26 & 26 & 26 & 26 \\
Tepung Ikan & 9,5 & 9,5 & 9,5 & 9,5 & 9,5 \\
Dedak padi & 5 & 3,75 & 2,5 & 1.25 & 0 \\
Bongggol Pisang Hasil Fermentasi & 0 & 1,25 & 2,5 & 3.75 & 5 \\
CPO & 2 & 2 & 2 & 2 & 2 \\
Tepung Tulang & 0,5 & 0,5 & 0,5 & 0,5 & 0,5 \\
Premix & 0,5 & 0,5 & 0,5 & 0,5 & 0,5 \\
\hline Jumlah (\%) & 100 & 100 & 100 & 100 & 100 \\
\hline
\end{tabular}

Alat yang digunakan untuk pengujian sifat fisik pellet adalah: timbangan analitik, gelas ukur 100 $\mathrm{ml}$, pengaduk, corong, jangka sorong, penggaris, alat pengukur sudut tumpukan.

Penelitian menggunakan metode eksperimental dengan Rancangan Acak Lengkap (RAL) yang terdiri dari 5 perlakuan dan 4 ulangan. Perlakuan pada penelitian ini adalah penggunaan berbagai taraf bonggol pisang ambon terfermentasi untuk menggantikan dedak padi dalam pellet.

\section{Peubah yang Diamati}

\section{Berat Jenis}

Berat jenis dihitung dengan rumus (Khalil, 1999) berikut :

$$
\text { Berat Jenis } \frac{\mathrm{g}}{\mathrm{cm}^{3}}=\frac{\text { Berat Bahan (gram) }}{\text { Perubahan Volume Air }\left(\mathrm{cm}^{3}\right)}
$$




\section{Sudut Tumpukan}

Besarnya sudut tumpukan dihitung dengan menggunakan rumus (Khalil, 1999) sebagai berikut :

$$
\operatorname{tg} \alpha=\frac{\mathrm{t}}{0,5 \mathrm{~d}}
$$

Keterangan : $\mathrm{t}=$ Tinggi tumpukan

$\mathrm{d}=$ Diameter tumpukan

$\alpha=$ Sudut tumpukan

\section{Kerapatan tumpukan}

Kerapatan tumpukan dihitung dengan rumus (Khalil, 1999) sebagai berikut :

$$
\text { Kerapatan tumpukan } \frac{\mathrm{g}}{\mathrm{cm}^{3}}=\frac{\text { Berat Bahan (gram) }}{\text { Volume ruang }\left(\mathrm{cm}^{3}\right)}
$$

\section{Kerapatan Pemadatan Tumpukan}

Kerapatan pemadatan tumpukan dihitung dengan rumus (Khalil, 1999) sebagai berikut :

Kerapatan Pemadatan Tumpukan $\frac{\mathrm{g}}{\mathrm{cm}^{3}}=\frac{\text { Berat Bahan (gram) }}{\left.\text { Volume Ruang Setelah Dipadatkan ( } \mathrm{cm}^{3}\right)}$

Perlakuan yang diberikan adalah sebagai berikut :

R0 = Dedak Padi $5 \%$, Bonggol Pisang Ambon terfermentasi $0 \%$

R1 = Dedak Padi $3.75 \%$, Bonggol Pisang Ambon terfermentasi $1.25 \%$

R2 = Dedak Padi $2.50 \%$, Bonggol Pisang Ambon terfermentasi $2.50 \%$

R3 = Dedak Padi 1.25\%, Bonggol Pisang Ambon Hasil Fermentasi $3.75 \%$

R4 = Dedak Padi $0 \%$, Bonggol Pisang Ambon Hasil Fermentasi $5 \%$

\section{Analisis Data}

Data yang diperoleh dianalisa secara statistika dengan analisis ragam menggunakan rumus matematika sebagai berikut (Hanafiah, 2003).

$$
Y i j=\mu+\alpha_{i}+€_{i j}
$$

Keterangan :

$\mathrm{Y}_{\mathrm{ij}}=$ Nilai pengamatan dari perlakuan ke-i dan ulangan ke-j

$\mu=$ Rataan umum

$\alpha_{\mathrm{i}}=$ Pengaruh perlakuan ke-i

$\epsilon_{\mathrm{ij}}=$ Pengaruh galat dari perlakuan ke-i dan ulangan ke-j

$\mathrm{I}=$ Banyaknya perlakuan $(\mathrm{i}=1,2,3,4,5)$

$\mathrm{J}=$ Banyaknya ulangan $(\mathrm{j}=1,2,3,4)$

Apabila Hasil sidik ragam menunjukkan pengaruh nyata, maka dilanjutkan dengan uji beda 2 ratarata, menggunakan uji lanjut DMRT (Duncan Multiple Range Test) dengan taraf signifikansi 5\%. 


\section{Hasil dan Pembahasan}

\section{Pengaruh Perlakuan terhadap Berat Jenis Pellet}

Rataan berat jenis dari hasil penelitian yang paling tinggi adalah perlakuan $\mathrm{R} 4\left(1,26 \mathrm{~g} / \mathrm{cm}^{3}\right)$, kemudian diikuti berturut-turut perlakuan R1 $\left(1,25 \mathrm{~g} / \mathrm{cm}^{3}\right), \mathrm{R} 0\left(1,24 \mathrm{~g} / \mathrm{cm}^{3}\right), \mathrm{R} 3\left(1,24 \mathrm{~g} / \mathrm{cm}^{3}\right)$ dan R2 $\left(1,22 \mathrm{~g} / \mathrm{cm}^{3}\right)$. Pengaruh perlakuan terhadap berat jenis pellet dapat diketahui dengan melakukan sidik ragam. Hasil sidik ragam menunjukkan bahwa substitusi dedak halus dengan bonggol pisang terfermentasi tidak berpengaruh nyata terhadap berat jenis. Hal ini memperlihatkan bahwa pemberian bonggol pisang hasil fermentasi dalam ransum tidak mempengaruhi berat jenis pellet. Hasil ini sesuai dengan penelitian Agustina (2005) yang menunjukkan bahwa berat jenis antara perlakuan baik pada mash maupun pellet menunjukkan hasil yang tidak berbeda nyata karena ruang antar partikel dalam mash maupun pellet sudah terisi air selama proses pengurangan ukuran partikel dan selama proses produksi berlangsung. Hasil yang sama diungkapkan oleh Nilasari (2012) bahwa berat jenis pada pellet tanpa penyimpanan tidak berbeda nyata antar perlakuan.

\section{Pengaruh Perlakuan terhadap Sudut Tumpukan}

Rataan sudut tumpukan dari hasil penelitian yang paling tinggi adalah perlakuan R3 $\left(24,07^{\circ}\right)$, kemudian diikuti berturut-turut perlakuan R2 $\left(23,43^{\circ}\right)$, R1 $\left(23,31^{\circ}\right)$, R4 $\left(22,74^{\circ}\right)$ dan R0 $\left(21,36^{\circ}\right)$. Pengaruh perlakuan terhadap sudut tumpukan pellet dapat diketahui dengan cara melakukan sidik ragam. Data hasil perhitungan sidik ragam menunjukkan bahwa substitusi dedak halus dengan bonggol pisang terfermentasi tidak berpengaruh nyata terhadap sudut tumpukkan pellet. Sudut tumpukan yang terbentuk pada perlakuan berkisar antara $21,36^{\circ}-24,07^{\circ}$. Hasil penelitian ini sesuai dengan Syamsu (2007) yang mengemukakan bawah penggunaan umbi gaplek tidak memberikan pengaruh yang nyata terhadap besarnya sudut tumpukan, hal ini salah satunya disebabkan oleh berat jenis pada penelitian ini tidak berbeda nyata, padahal semakin tinggi berat jenis semakin tinggi sudut tumpukan. Selain itu, Baryeh (2002) menyatakan bahwa nilai sudut tumpukan dipengaruhi oleh kadar air, semakin tinggi kadar air maka akan meningkatkan nilai sudut tumpukan.

\section{Pengaruh Perlakuan terhadap Kerapatan Tumpukkan}

Rataan kerapatan tumpukan pellet dari hasil penelitian yang paling tinggi adalah perlakuan R0 $\left(0,64 \mathrm{~g} / \mathrm{cm}^{3}\right)$ dan R1 $\left(0,64 \mathrm{~g} / \mathrm{cm}^{3}\right)$, kemudian diikuti berturut-turut perlakuan R2 $\left(0,61 \mathrm{~g} / \mathrm{cm}^{3}\right), \mathrm{R} 4$ $\left(0,60 \mathrm{~g} / \mathrm{cm}^{3}\right)$, dan R3 $\left(0,59 \mathrm{~g} / \mathrm{cm}^{3}\right)$. Pengaruh substitusi dedak halus dengan bonggol pisang terfermentasi terhadap kerapatan tumpukan pellet, dapat dilihat diketahui dengan melakukan sidik ragam. Data hasil perhitungan sidik ragam menunjukkan bahwa substitusi dedak padi dengan bonggol pisang terfermentasi berpengaruh nyata terhadap kerapatan tumpukkan pellet. Selanjutnya untuk mengetahui perbedaan pengaruh antara perlakuan, dilakukan Uji Jarak Berganda Duncan yang hasilnya dapat dilihat pada Tabel 2.

Berdasarkan data hasil perhitungan Uji Jarak Berganda Duncan, terlihat bahwa rataan kerapatan tumpukan pellet pada perlakuan $\mathrm{R} 3\left(0,59 \mathrm{~g} / \mathrm{cm}^{3}\right)$ berbeda dibandingkan dengan perlakuan $\mathrm{R} 2$ $\left(0,61 \mathrm{~g} / \mathrm{cm}^{3}\right), \mathrm{R} 0\left(0,64 \mathrm{~g} / \mathrm{cm}^{3}\right)$, dan juga R1 $\left(0,64 \mathrm{~g} / \mathrm{cm}^{3}\right)$, namun masih tidak berbeda dengan perlakuan R4 $\left(0,60 \mathrm{~g} / \mathrm{cm}^{3}\right)$. Perlakuan R4 $\left(0,60 \mathrm{~g} / \mathrm{cm}^{3}\right)$ berbeda dibandingkan perlakuan R0 $(0,64$ $\left.\mathrm{g} / \mathrm{cm}^{3}\right)$ dan R1 $\left(0,64 \mathrm{~g} / \mathrm{cm}^{3}\right)$, namun masih tidak berbeda dengan perlakuan $\mathrm{R} 3\left(0,59 \mathrm{~g} / \mathrm{cm}^{3}\right)$ dan $\mathrm{R} 2\left(0,61 \mathrm{~g} / \mathrm{cm}^{3}\right)$. Perlakuan R2 $\left(0,61 \mathrm{~g} / \mathrm{cm}^{3}\right)$ berbeda jika dibandingkan dengan perlakuan R0 $\left(0,64 \mathrm{~g} / \mathrm{cm}^{3}\right)$ dan $\mathrm{R} 1\left(0,64 \mathrm{~g} / \mathrm{cm}^{3}\right)$ yang memiliki nilai kerapatan tumpukan sama. 
Tabel 2. Hasil Uji Jarak Berganda Duncan Pengaruh Perlakuan terhadap Kerapatan Tumpukan Pellet

\begin{tabular}{llc}
\hline Perlakuan & Rataan $\left(\mathrm{g} / \mathrm{cm}^{3)}\right.$ & Signifikansi \\
& 0,05 \\
\hline R3 & 0,59 & $\mathrm{a}$ \\
R4 & 0,60 & $\mathrm{ab}$ \\
R2 & 0,61 & $\mathrm{~b}$ \\
R0 & 0,64 & $\mathrm{c}$ \\
R1 & 0,64 & $\mathrm{c}$ \\
\hline
\end{tabular}

Nilai kerapatan tumpukan menunjukkan porositas dari bahan yaitu jumlah rongga udara yang terdapat di antara partikel-partikel bahan (Khalil, 1999). Kerapatan tumpukan akan semakin meningkat dengan semakin banyak jumlah partikel halus dalam suatu ransum (Johnson, 1994). Menurut Suadnyana (1998), nilai kerapatan tumpukan menurun dengan semakin meningkatnya kadar air karena bahan akan mengembang dengan semakin tingginya kandungan air sehingga volume ruang yang dibutuhkan menjadi besar.

Pellet dengan kandungan bonggol pisang yang semakin tinggi membuatnya semakin mudah mengembang, hal tersebut disebabkan karena bonggol pisang memiliki kandungan air yang lebih tinggi yaitu sebesar 15,37 \% dibandingkan dengan dedak padi dengan kadar air sebesar 9\% (Dewan Standarisasi Nasional, 2001). Persentase substitusi dedak padi dengan bonggol pisang terfermentasi yang semakin banyak menjadi faktor penyebab yang menurunkan kerapatan tumpukan pellet.

Faktor lain yang mempengaruhi nilai kerapatan tumpukan pellet adalah kandungan serat kasar. Bonggol pisang merupakan limbah dari tanaman pisang yang berserat tinggi. Partikel serat dari bahannya adalah kasar sehingga menyebabkan kerapatan tumpukan semakin menurun dan disertai adanya peningkatan kadar air yang masuk ke pori-pori tepung bonggol pisang yang sangat halus. Semakin tinggi kandungan bonggol pisang dalam pellet, maka kandungan serat kasar pada pellet semakin tinggi begitupun sebaliknya.

Kadar air dan serat kasar yang lebih rendah pada perlakuan R0 dan R1 membuat perlakuan R0 dan R1 memiliki nilai kerapatan tumpukan yang lebih tinggi dibandingkan perlakuan lainnya. Nilai kerapatan tumpukan menunjukkan porositas bahan, yaitu jumlah rongga udara yang terdapat diantara partikel-partikel bahan (Wirakartakusumah dkk., 1992). Semakin tinggi nilai kerapatan tumpukan maka ruang penyimpanan yang dibutuhkan semakin kecil (Khalil, 1999).

\section{Pengaruh Perlakuan terhadap Kerapatan Pemadatan Tumpukan Pellet}

Rataan kerapatan pemadatan tumpukan pellet dari hasil penelitian yang paling tinggi adalah perlakuan R0 $\left(0,65 \mathrm{~g} / \mathrm{cm}^{3}\right)$ dan $\mathrm{R} 1\left(0,65 \mathrm{~g} / \mathrm{cm}^{3}\right)$, kemudian diikuti berturut-turut perlakuan R2 $\left(0,63 \mathrm{~g} / \mathrm{cm}^{3}\right)$, R4 $\left(0,61 \mathrm{~g} / \mathrm{cm}^{3}\right)$, dan R3 $\left(0,60 \mathrm{~g} / \mathrm{cm}^{3}\right)$. Pengaruh penggunaan bonggol pisang terfermentasi terhadap kerapatan pemadatan tumpukan pellet, dapat diketahui dengan melakukan sidik. Data hasil perhitungan sidik ragam pada menunjukkan bahwa substitusi dedak padi dengan bonggol pisang terfermentasi dalam pellet memberikan pengaruh nyata terhadap kerapatan pemadatan tumpukan pellet. Selanjutnya untuk mengetahui perbedaan pengaruh antara perlakuan, dilakukan Uji Jarak Berganda Duncan yang hasilnya terdapat pada Tabel 3. 
Tabel 3. Hasil Uji Jarak Berganda Duncan Pengaruh Perlakuan terhadap Kerapatan Pemadatan Tumpukan Pellet

\begin{tabular}{|c|c|c|}
\hline Perlakuan & Rataan $\left(\mathrm{g} / \mathrm{cm}^{3}\right)$ & $\begin{array}{l}\text { Signifikansi } \\
0,05\end{array}$ \\
\hline R3 & 0,60 & A \\
\hline $\mathrm{R} 4$ & 0,61 & $\mathrm{Ab}$ \\
\hline $\mathrm{R} 2$ & 0,63 & $\mathrm{Bc}$ \\
\hline R0 & 0,65 & $\mathrm{C}$ \\
\hline R1 & 0,65 & $\mathrm{C}$ \\
\hline
\end{tabular}

Berdasarkan hasil perhitungan Uji Jarak Berganda Duncan diatas, terlihat bahwa rataan kerapatan pemadatan tumpukan pellet pada perlakuan R3 $\left(0,60 \mathrm{~g} / \mathrm{cm}^{3}\right)$ berbeda dibandingkan dengan perlakuan R2 $\left(0,63 \mathrm{~g} / \mathrm{cm}^{3}\right), \mathrm{R} 0\left(0,65 \mathrm{~g} / \mathrm{cm}^{3}\right)$, dan juga R1 $\left(0,65 \mathrm{~g} / \mathrm{cm}^{3}\right)$, namun masih tidak berbeda dengan perlakuan R4 $\left(0,61 \mathrm{~g} / \mathrm{cm}^{3}\right)$. Perlakuan R4 $\left(0,61 \mathrm{~g} / \mathrm{cm}^{3}\right)$ berbeda dibandingkan perlakuan R0 $\left(0,65 \mathrm{~g} / \mathrm{cm}^{3}\right)$ dan R1 $\left(0,65 \mathrm{~g} / \mathrm{cm}^{3}\right)$, namun masih tidak berbeda dengan perlakuan R3 $(0,60$ $\left.\mathrm{g} / \mathrm{cm}^{3}\right)$ dan R2 $\left(0,63 \mathrm{~g} / \mathrm{cm}^{3}\right)$. Perlakuan R2 $\left(0,63 \mathrm{~g} / \mathrm{cm}^{3}\right)$, R0 $\left(0,65 \mathrm{~g} / \mathrm{cm}^{3}\right)$, dan R1 $\left(0,65 \mathrm{~g} / \mathrm{cm}^{3}\right)$ memiliki nilai kerapatan pemadatan tumpukan yang tidak berbeda.

Kerapatan pemadatan tumpukan dan kerapatan tumpukan pellet menunjukkan korelasi positif, semakin tinggi nilai kerapatan tumpukan maka kerapatan pemadatan tumpukan akan semakin tinggi dan sebaliknya. Hasil penelitian menunjukkan bahwa kerapatan pemadatan tumpukan cenderung meningkat antar perlakuan, hal tersebut dikarenakan kadar air pellet yang semakin tinggi menyebabkan berat pellet tiap satuan volume menjadi meningkat sehingga tingkat pemadatan pellet menjadi meningkat. Menurut Sayekti (1999), kerapatan pemadatan tumpukan dipengaruhi oleh kadar air dan ukuran partikel.

Kadar air yang lebih rendah pada perlakuan R0 dan R1 membuat perlakuan R0 dan R1 memiliki nilai kerapatan pemadatan tumpukan yang lebih tinggi dibandingkan perlakuan lainnya. Khalil (1999) menyatakan bahwa semakin tinggi nilai kerapatan pemadatan tumpukan maka ruang penyimpanan yang dibutuhkan semakin kecil dan juga proses pengangkutan menjadi semakin mudah.

\section{$4 \quad$ Kesimpulan}

Berdasarkan hasil penelitian yang telah dilakukan maka dapat ditarik kesimpulan bahwa pengaruh substitusi dedak padi dengan bonggol pisang ambon terfermentasi $1.25 \%$ berpengaruh nyata meningkatkan sifat fisik pellet kerapatan dan kerapatan pemadatan tumpukkan namun tidak berpengaruh nyata terhadap berat jenis dan sudut tumpukkan pellet

\section{$5 \quad$ Daftar Pustaka}

Agustina, Y. 2005. Kualitas Fisik Pellet Ransum Ayam Broiler Mengandung Bahan dengan Ukuran Partikel yang Berbeda Pada Proses Produksi Berkesinambungan. Skripsi. Fakultas Peternakan. Institut Pertanian Bogor. Bogor

Baryeh, E.A. 2002. Physical Properties of Millet. .Journal of Food Engineering. 51(1):39-46 
Standarisasi Nasional Indonesia. 2013. Dedak Padi Bahan Baku Pakan. BSN. Jakarta

Hanafiah, A.H. 2003. Rancangan Percobaan Teori dan Aplikasi. Edisi III. PT. RajaGrafindo Persada. Jakarta.

Johnson, J. R. 1994. The Realities of Bulk Solid Properties Testing. Bulk Solid Handling. J. Anim. Sci. 14 (1) : 129-132.

Khalil. 1999. Pengaruh kandungan air dan ukuran partikel terhadap perubahan perilaku fisik bahan pakan lokal: kerapatan tumpukan, kerapatan pemadatan tumpukan, dan berat jenis. Media Peternakan 22 (1):1-11.

Nilasari. 2012. Pengaruh Penggunaan Tepung Ubi Jalar, Garut dan Onggok terhadap Sifat Fisik dan Lama Penyimpanan Pellet. Skripsi. Bogor (ID): Institut Pertanian Bogor.

Sayekti, W. B. R. 1999. Karakteristik Sifat Fisik Berbagai Varietas Jagung (Zea mayz). Skripsi. Fakultas Peternakan. Institut Pertanian Bogor, Bogor.

Suadnyana, I. W. 1998. Pengaruh Kandungan Air dan Ukuran Partikel terhadap Perubahan Sifat Fisik Pakan Lokal Sumber Protein. Skripsi. Fakultas Peternakan. Institut Pertanian Bogor, Bogor.

Sunarto, Sulistyani, dan S. Marwati. 2013. Pemanfaatan Limbah Bonggol Pisang Sebagai Bahan Baku Pembuatan Bioetanol. Jurnal Sains Dasar. Fakultas MIPA Universitas Negeri Yogyakarta.

Syamsu J. A. 2007. Karakteristik Fisik Pellet pakan Itik Bentuk Pellet yang diberi bahjan perekat Berbeda dan Lama penyimpanan yang Berbeda. Jurnal Ilmu Ternak. Vol, 7 No 2, 128134.

Wirakartakusumah, M. A., K. Abdullah, \& A. M. Syarif. 1992. Sifat Fisik Pangan. Depdikbud. Direktorat Jenderal Pendidikan Tinggi. Pusat Antar Universitas Pangan dan Gizi. Institut Pertanian Bogor. Bogor. 